\title{
Tracheotomy pada anjing American Pit Bull Terrier yang men- galami vulnus morsum
}

\author{
Kenan Wisnu Chrisnanta*, Arni Diana Fitri \\ Rumah Sakit Hewan Pendidikan, Fakultas Kedokteran Hewan, Institut Pertanian Bogor, Bogor, Jawa Barat
}

\begin{abstract}
ABSTRAK: Vulnus morsum atau luka akibat gigitan hewan pada regio cranium dan cervic di anjing trah medium dan besar sering terjadi akibat perkelahian. Apabila tidak segera dilakukan penanganan dapat berakibat fatal. Tulisan ini melaporkan kasus luka di leher seekor anjing American Pit Bull Terrier akibat perkelahian dengan anjing lain sejenis. Pemilik membawa anjing ke Rumah Sakit Hewan Pendidikan (RSHP) Fakultas Kedokteran Hewan (FKH) Institut Pertanian Bogor (IPB) dengan kondisi luka-luka terbuka di area leher disertai perdarahan yang cukup hebat. Luka akibat gigitan tersebut sangat parah, muskulus daerah leher terkoyak, terjadi perdarahan, dan terjadi tracheal rupture. Penanganan dilakukan dengan ligasi pembuluh darah yang mengalami perdarahan, bedah tracheotomy, serta penjahitan luka-luka yang terbuka. Luka tertutup dengan baik dan dirawat inap di RSHP FKH IPB selama 2 hari, kemudian atas keinginan pemilik dibawa pulang untuk dirawat secara mandiri oleh pemilik.
\end{abstract}

Kata kunci:

American Pit Bull Terrier, vulnus morsum, tracheotomy

\section{- PENDAHULUAN}

Vulnus morsum merupakan luka mekanik yang diakibatkan oleh gigitan hewan, umumnya akibat gigitan anjing. Luka yang ditimbulkan memiliki sifat vulnus punctum; luka akibat tusukan benda tajam, dan vulnus laceratum; luka sobek atau sayatan. Derajat keparahan vulnus morsum tergantung dari gerakan mekanik hewan penggigit, semakin dalam dan kuat cengkraman rahang hewan tersebut, maka luka yang dihasilkan akan semakin parah, bahkan dapat menyebabkan kematian (Fekete dan Zsiros, 2008).

Menurut United Kennel Club (1978), anjing jenis American Pit Bull Terrier memiliki karakteristik fisik yang kuat, badan yang kekar, serta rahang yang kuat. Secara psikologis, anjing ini cukup pandai dan bersemangat, namun juga sangat agresif. Oleh karena karakteristik dan juga sifat yang sangat kuat dan agresif, kasus gigitan oleh anjing American Pit Bull Terrier sering terjadi, baik ke sesama anjing, maupun kepada manusia. Tulisan ini melaporkan sebuah kasus gigitan pada anjing dan proses penanganannya.

\section{- KASUS}

Anamnesa dan sinyalemen: Seekor anjing American Pit Bull Terrier betina bernama Hansen, usia 3 tahun, datang ke Rumah Sakit Hewan Pendidikan (RSHP) Fakultas Kedokteran Hewan (FKH) Institut Pertanian Bogor (IPB) dengan kondisi luka-luka terbuka di area leher disertai perdarahan yang cukup hebat (Gambar 1). Menurut pemilik, anjing Hansen sedang dalam kondisi terikat ketika anjing American Pitt Bull Terrier lainnya terlepas dari kandang, dan langsung menyerang anjing Hensen. Anjing Hensen digigit pada bagian leher, luka terbuka dan terjadi perdarahan. Pemeriksaan Fisik: Berat badan $30,35 \mathrm{~kg}$, Suhu rektal $38,6^{\circ} \mathrm{C}$, frekuensi nafas $16 \mathrm{kali} /$ menit, frekuensi jantung 148 kali/menit. Diagnosa: vulnus morsum. Prognosa: Dubius-infausta. Terapi dan Penanganan: Penjahitan luka dengan benang Vicryl ${ }^{\circledR} 3.0$ dan 2.0, antibiotic Amoxicillin ${ }^{\circledR}$, analgesik dan antiradang Dexamethasone ${ }^{\circledR}$ dan Meloxicam ${ }^{\circledR}$, secara injeksi dan dilanjut peroral, serta Vitamin dan suplemen Biodin ${ }^{\circledR}$ dan Hematodin $®$ injeksi diikuti Sangobion ${ }^{\circledR}$ peroral.

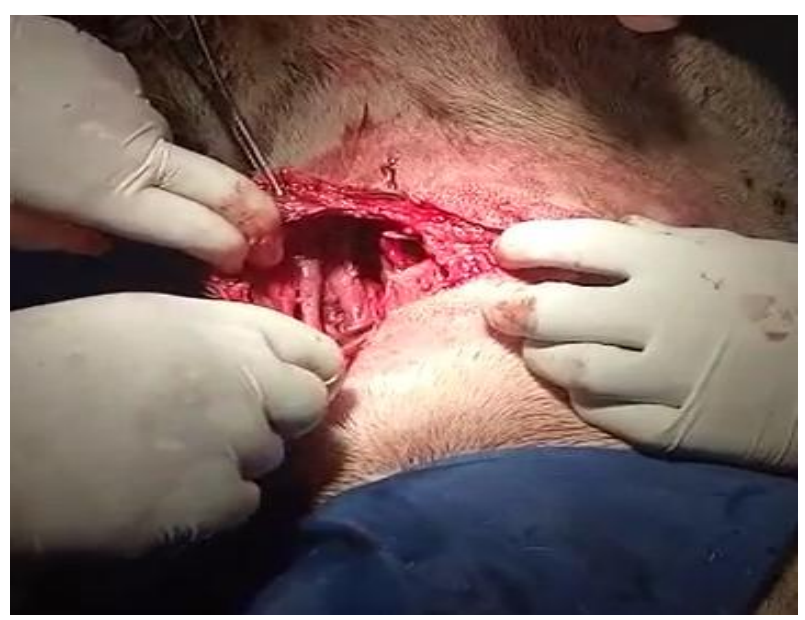

Gambar 1 Vulnus morsum pada anjing American Pit Bull Terrier

Diterima: 19-09-2018 | Direvisi: 29-10-2018 | Disetujui: 07-11-2018 (C) 2018 CC-BY-SA. Ini adalah artikel Open Access yang didistribusikan berdasarkan ketentuan dari Creative Commons Attribution ShareAlike 4.0 International License (https://creativecommons.org/licenses/by-sa/4.0/). 


\section{- HASIL DAN PEMBAHASAN}

Anjing Hensen datang ke RSHP FKH IPB dengan kondisi perdarahan pada daerah leher, nafas dypsnoe, kondisi lemas dan sangat lemah. Setelah dilakukan pemeriksaan fisik, ditemukan luka-luka terbuka dibagian leher. Ketika luka sedang dibersihkan, ditemukan kondisi trakhea Hansen rupture sekitar $2 \mathrm{~cm}$, sehingga teramati anjing Hensen tidak dapat bernafas dengan normal melalui hidungnya.

Anjing Hansen kemudian dianestesi menggunakan kombinasi Ketamine ${ }^{\circledR}$ dan Acepromazine ${ }^{\circledR}$ untuk mempermudah penanganan luka serta pemasangan infus Ringger Laktat ${ }^{\circledR}$ secara intravena. Setelah teranestesi, rambut di sekitar luka dicukur dan dilanjutkan pembersihan luka dengan $\mathrm{NaCl}$ fisiologis. Luka dibuka lebih lebar untuk mempermudah proses penanganan (Gambar 2). Irigasi menggunakan $\mathrm{NaCl}$ fisiologis dilakukan untuk membersihkan luka. Arteri carotis communis dan vena jugularis sebagai pembuluh darah utama di regio cervicalis, ditemukan tidak mengalami kerusakan. Namun beberapa pembuluh darah yang lebih kecil disekitarnya mengalami perdarahan sehingga dilakukan ligasi terlebih dahulu. Menurut Basdani et al. (2016), regio cranial dan cervical merupakan daerah yang paling sering mengalami luka gigitan pada anjing trah medium dan besar.
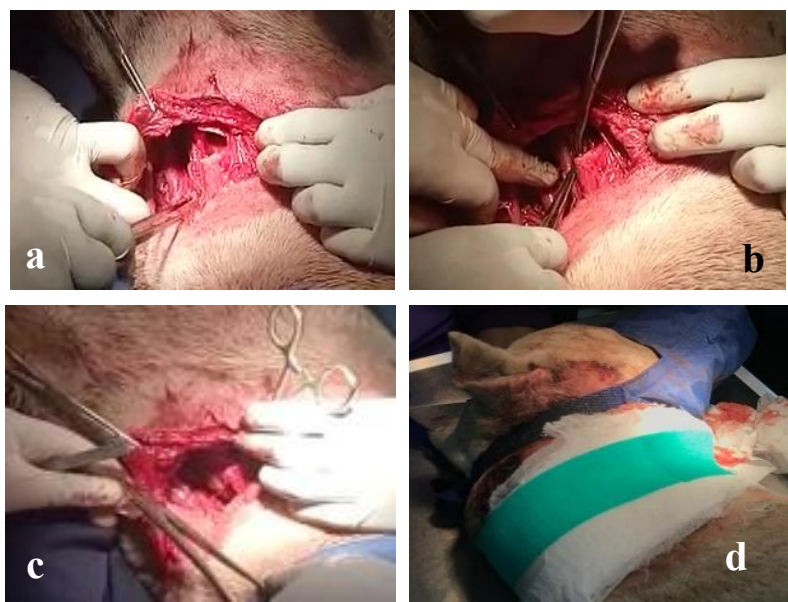

Gambar 2 Prosedur bedah penanganan luka pada leher anjing Hansen. (a) Penyayatan luka terbuka, (b) ligasi pembuluh darah yang mengalami perdarahan, (c) penjahitan trachea yang ruptur (d) pembalutan luka pascabedah

Luka disekitar trakhea yang sudah dibersihkan, kemudian difiksasi terlebih dahulu sebelum dijahit. Trakhea yang mengalami rupture dirapatkan kembali diantara kedua ujung tepi luka dan dijahit dengan pola simple interupted menggunakan benang Vicryl 2.0®. Pola jahitan simple interrupted digunakan pada sebagian besar kasus luka seperti ini, karena meminimalisirkan terjadinya luminal stenosis pada trakhea (Basdani et al. 2016). Setelah trakhea dijahit dengan sempurna, anjing Hensen sudah dapat bernafas kembali dengan normal melalui hidung. Proses penutupan luka dilanjutkan kembali dengan menjahit jaringan fascia pada perototan di regio cervicalis dan diakhiri dengan jahitan intradermal.

Anjing Hansen diberikan injeksi antibiotic Betamox LA®, Hematodin ${ }^{\circledR} \quad$ dan $\quad$ Biodin ${ }^{\circledR} \quad$ sebagai supplement multivitamin, mineral dan hematopoetika, serta Dexamethasone ${ }^{\circledR}$ dan Meloxicam ${ }^{\circledR}$ setelah tindakan bedah sebagai analgesik dan antiinflamasi. Pengobatan dilanjutkan dengan pemberian sediaan yang sama secara peroral. Hansen dirawat inap selama 2 hari, kemudian atas keinginan pemilik dibawa pulang untuk dirawat secara mandiri oleh pemilik.

\section{- SIMPULAN}

Luka gigitan di regio cranium dan cervic sering terjadi pada anjing trah medium dan besar. Luka yang ditimbulkan berupa laserasi, terkoyak, bahkan fraktur. Tindakan bedah dapat dilakukan untuk penanganan. Jika penangan luka tidak segera dilakukan, akan berakibat fatal.

\section{- INFORMASI PENULIS}

Penulis untuk Korespondensi

*KWC: kenanwisnu@gmail.com

Rumah Sakit Hewan Pendidikan, Fakultas Kedokteran Hewan Institut Pertanian Bogor, Jalan Agatis Kampus IPB Dramaga Bogor 16680

\section{- PUSTAKA ACUAN}

András F, Lajos Z. 2008. Analysis and post-exposure management of mammalian bite injuries in the Hungarian Central Military Hospital. Medicine, 7(3): 523-533.

Basdani E, Papazoglou LG, Patsikas MN, Kazakos GM, Adamama-Moraitou KK, Tsokataridis I. 2016. Upper airway injury in dogs secondary to trauma: 10 dogs (2000-2011). Journal of the American Animal Hospital Association, 52(5): 291-296.

United Kennel Club. 1978. American Pit Bull Terrier, official Breed Standard. 